\title{
Box-Behnken Design Assisted Protein Precipitation Optimization for Simultaneous Determination of Metformin Hydrochloride and Alogliptin Benzoate in Plasma along with Pharmacokinetic Application
}

\author{
H. P. PATEL, D. P. PATEL, J. R. CHRISTIAN, P. A. SHAH, K. G. PATEL*AND T. R. GANDHI \\ Department of Quality Assurance, Anand Pharmacy College, Anand, Gujarat 388001, India
}

Patel et al.: Simultaneous Determination of Metformin Hydrochloride and Alogliptin Benzoate in Plasma

\begin{abstract}
The study focuses on systematic quality by design oriented approach for the optimization of a sensitive reverse phase liquid chromatographic bioanalytical method for determination of metformin hydrochloride and alogliptin benzoate in plasma along with its validation. Chromatographic separation was carried out on $\mathrm{C}_{18}$ column using gradient mode with mobile phase; 1-octane sulphonic acid $(10 \mathrm{mM})$, acetonitrile and phosphate buffer $\mathrm{pH} 4$, adjusted by orthophosphoric acid, at $1.0 \mathrm{ml} / \mathrm{min}$ using $235 \mathrm{~nm}$ as detection wavelength. A Box-Behnken design was applied to protein precipitation sample extraction method with centrifugation speed, centrifugation time and volume of plasma as the critical method parameters for maximizing percentage extraction recovery of metformin hydrochloride and alogliptin benzoate as the critical analytical attributes. The optimized condition for centrifugation speed, centrifugation time and volume of plasma considered as the critical method parameters for maximizing extraction recovery were $11800 \mathrm{rpm}, 15 \mathrm{~min}, 100 \mu \mathrm{l}$. This optimized extraction method gave clear samples and resulted in good correlation in the concentration range of $0.022-2.2$ and $0.0012-0.12 \mu \mathrm{g} / \mathrm{ml}$ for metformin hydrochloride and alogliptin benzoate, respectively. The mean percentage extraction recoveries at three quality control levels were 90.83-95.87 \% for metformin hydrochloride and 94.03-96.73\% for alogliptin benzoate. The plasma concentration time profile showed higher peak plasma concentration for formulation compared to pure drugs indicating that absorption of metformin and alogliptin hydrochloride from formulation was better. The developed liquid chromatographic method presented good quantitative capability, good linearity, higher extraction recovery, simpler operation and short analysis time with low cost.
\end{abstract}

Key words: Metformin hydrochloride, alogliptin benzoate, high performance liquid chromatography, Box-Behnken design, pharmacokinetic, plasma, validation

Metformin hydrochloride (MET), an oral antidiabetic drug belongs to biguanide class and is $\mathrm{N}, \mathrm{N}$-dimethyl imido-carbonimidic diamide hydrochloride ${ }^{[1]}$. It is the first-line drug of choice for the treatment of type 2 diabetes and acts by inhibiting hepatic glucose production, gluconeogenesis and increasing peripheral utilization of glucose. Alogliptin benzoate (ALO), a novel hypoglycemic drug and dipeptidyl-peptidase-4 inhibitor is 2-(\{6-[(3R)-3-aminopiperidin-1-yl]-3methyl-2,4-dioxo-3,4-dihydropyrimidin-1(2H)-yl $\}$ methyl) benzo nitrile mono benzoate. It stimulates glucose-dependent insulin release ${ }^{[2]}$. Several high performance liquid chromatography (HPLC) methods have been reported individually and in combination

*Address for correspondence E-mail: kalpanapatel.pharma@gmail.com for the estimation of MET and $\mathrm{ALO}^{[3-6]}$ and with other drugs in bulk and plasma. Also literature reports a method for the simultaneous determination of MET and ALO in human plasma by reverse phase high performance liquid chromatography (RP-HPLC) ${ }^{[7]}$. The development of bioanalytical method employing a holistic quality by design ( $\mathrm{QbD}$ ) approach is gaining wide popularity. Based on the principles of sound

This is an open access article distributed under the terms of the Creative Commons Attribution-NonCommercial-ShareAlike 3.0 License, which allows others to remix, tweak, and build upon the work non-commercially, as long as the author is credited and the new creations are licensed under the identical terms

Accepted 10 August 2021

Revised 01 February 2021

Received 13 March 2020 Indian J Pharm Sci 2021;83(4):785-793 
science and quality risk management, $\mathrm{QbD}$ approach enables, enhanced understanding of the critical method parameters (CMPs) influencing the critical analytical attributes (CAAs) and ultimately the method performance. The design of experiment (DOE) is a systematic strategy constituting the integral elements of $\mathrm{QbD}$ by assisting in optimizing critical process parameters (CPP), while expending minimal resources of time, effort and $\cos ^{\left[{ }^{[8]}\right.}$. Sample preparation is an integral part of optimization of bioanalytical method and various offline sample clean up procedures like protein precipitation (PP), liquid-liquid extraction (LLE) and solid-phase extraction (SPE) are most widely used. PP is simple and applicable to both hydrophilic and hydrophobic compounds, but the supernatant is relatively unclean since it still contains a significant amount of unprecipitated soluble plasma components that could affect chromatographic separation or suppress the ionization of the target analyte. SPE works with most compounds but suffers from having a complicated and time-consuming procedure, relatively poor reproducibility and is expensive. LLE is simple and the extracts are clean, but the recovery percentage of drug is less and it is generally unsuitable for the hydrophilic and thermolabile substances ${ }^{[9]}$. The studies were carried out to optimize the bioanalytical PP sample extraction method by Box-Behnken design (BBD) for obtaining maximum MET and ALO recovery from the biological matrix with superior method performance. Attempts, therefore, were made to develop and validate a rapid, sensitive, robust and economical bioanalytical HPLC method for the simultaneous estimation of MET and ALO in rat plasma using QbD-assisted systematic analytical approach.

\section{MATERIALS AND METHODS}

\section{Materials:}

MET and ALO were procured as a gratis sample from Alembic Pharmaceutical Ltd., Vadodara, India and Teneligliptin hydrobromide hydrate (TEN) was procured from Pure Chem. Pvt. Ltd., Ankleshwar, India. HPLC grade solvents, potassium dihydrogen orthophosphate, triethylamine and orthophosphoric acid from Merck, Mumbai, India were used. Milli-Q water was procured from sophisticated instrumentation centre for applied research and testing, Vallabh Vidyanagar. SPE cartridges [Oasis ${ }^{\circledR}$ hydrophilic-lipophilic balance (HLB) cartridges $(1 \mathrm{ml})$ were purchased from Waters, Bangalore (AGB, Belfast). Drug-free human plasma was obtained from Indian red cross society, Anand,
India and further stored in polypropylene bottle in deep freeze at $-20^{\circ}$ until analysis.

\section{Instrument:}

The research study was performed on HPLC system (Shimadzu LC-2010 CHT; Japan), with photodiodearray (PDA) detector and an auto sampler. The data were recorded using LC-2010 solutions software version 1.25. Weighing was carried out on analytical balance (Shimadzu AUW220 balance, Japan). Bioanalytical sample preparation was facilitated with refrigerated centrifuge (TC450 D; Eltek, Mumbai, India), Cyclo Mixer (Remi motors CM101; Mumbai, India).

\section{Chromatographic conditions:}

For optimization and adequate separation of both drugs in terms of resolution as per United States Pharmacopeia (USP) system suitability testing parameters, various solvents such as methanol, acetonitrile and water were tried using buffer systems of different $\mathrm{pH}$ in the range of 3.5 to 4.5. Potassium dihydrogen orthophosphate buffer $\mathrm{pH} 4$ gave good resolution and further different ratios were tried. Separation was performed on Phenomenex $\mathrm{C}_{18}$ column $(250 \times 4.60 \mathrm{~mm}, 5 \mu \mathrm{m})$ chemically bonded to porous silica. The mobile phase prepared was degassed and filtered using vacuum filtration assembly (TID 15; Mumbai, India) and Axiva Nylon membrane filters $(0.45$ and $0.2 \mu \mathrm{m})$ respectively. TEN was used as an internal standard.

\section{Preparation of calibration standards and quality control (QC) samples:}

Accurately weighed $10 \mathrm{mg}$ of each drug was dissolved separately in methanol in $10 \mathrm{ml}$ volumetric flask to obtain a standard stock solution of MET, ALO and TEN $(1000 \mu \mathrm{g} / \mathrm{ml})$ followed by storage at $-20^{\circ}$. Further dilution was carried out for preparation of working standard solution of MET and ALO $(100 \mu \mathrm{g} / \mathrm{ml})$. Calibration standards $(0.22-22$ and $0.0012-0.12 \mu \mathrm{g} / \mathrm{ml}$ for MET and ALO) were further achieved by spiking working standard solution to drug free plasma in $2 \mathrm{ml}$ graduated radioimmunoassay (RIA) vials. Additionally, three QC sample levels, namely, high, medium and low $(1.5,0.45$ and $0.045 \mu \mathrm{g} / \mathrm{ml}$ for MET and $0.09,0.024$ and $0.0024 \mu \mathrm{g} / \mathrm{ml}$ for ALO) were prepared. All the solutions of calibration standards and QC level samples were further stored in a deep freezer at $-20 \pm 2^{\circ}$ until analysis. 


\section{Selection of sample preparation technique:}

Sample preparation technique plays a key role in optimization of bioanalytical estimations. In context to this, various preliminary trials were performed using SPE and PP method with the sole objective of enhancing extraction recovery of both drugs. The samples and standards were prepared as described above and extracted using Oasis ${ }^{\circledR}$ HLB cartridges by SPE technique. Briefly, the cartridge was activated by methanol followed by water. Further plasma spiked with drugs was passed and further washing with $2 \%$ methanol followed by elution using methanol.

In PP method, on the basis of reported literature methanol, acetonitrile and combination of methanol and acetonitrile in different ratio (1:1, 1:2 and 2:1) were tried for the selection of the best extraction solvent. The extraction recovery of MET, ALO and TEN using different solvents was performed. The frozen samples were thawed in water bath at room temperature. The drug spiked thawed plasma $(100 \mu \mathrm{l})$ was taken into pre-labeled RIA vial and further vortexed to ensure complete mixing of contents for 2 min. TEN solution $(5 \mu \mathrm{g} / \mathrm{ml})$ was added followed by $1000 \mu \mathrm{l}$ of above mentioned extraction solvents. The mixture was finally vortexed for further $5 \mathrm{~min}$ to ensure uniform mixing. The vials were placed in refrigerated cooling centrifuge and centrifuged at $3000 \mathrm{rpm}$ for $5 \mathrm{~min}$ at $-20 \pm 2^{\circ}$. The supernatant was collected and filtered through $0.2 \mu \mathrm{m}$ nylon membrane filter. $20 \mu \mathrm{l}$ of the filtrate solution was further injected for determination by RP-HPLC.

\section{Optimization of PP using BBD:}

A multivariate optimization approach was used where levels of all the variables were changed and used to study the simultaneous variation effect of the factors on the responses by applying DOE. In present study, BBD was applied for the optimization of extraction procedure. $\mathrm{BBD}$ is a useful method for developing second-order response surface models, hence 3 factors were studied at 3 levels and hence total 17 experimental runs were designed. In the present study, three factors; centrifugation speed, centrifugation time and volume of plasma were selected and the ranges for factors were selected on the basis of results of preliminary experimental trials; extraction recovery at different centrifugation speed, centrifugation time and different volumes of plasma. In the present study, the lower and higher level for centrifugation speed were 6000 and $12000 \mathrm{rpm}$, for centrifugation time were 5 and $15 \mathrm{~min}$ and volume of plasma were 100 and $300 \mu \mathrm{l}$ (Table 1). The percentage recovery of MET and ALO was chosen as the CAA.

\section{Method validation:}

The developed bioanalytical method was validated as per US Food and Drug Administration (FDA) guideline ${ }^{[10]}$. The linearity was established by construction of calibration curve in the range of $0.022-2.2 \mu \mathrm{g} / \mathrm{ml}$ for MET and 0.0012-0.12 $\mu \mathrm{g} / \mathrm{ml}$ for $\mathrm{ALO}$ in the form of peak area ratio plotted against concentration. Moreover, homoscedasticity of data in terms of variance was evaluated by Bartlett's test ${ }^{[11,12]}$. The sensitivity, in terms of lower limit of quantification (LLOQ) and limit of detection (LOD) was determined and expressed as percentage coefficient of variation $(\% \mathrm{CV})$. The selectivity at LLOQ was evaluated for extraction recovery from two different blank plasma lots. The accuracy and precision was determined at three QC levels for both the drugs by injecting five replicates and expressed in terms of \% CV. Extraction recovery was performed at three QC levels before and after extraction in five replicates. Stability of MET and ALO under various storage conditions were investigated. Freeze thaw stability study was assessed at lower quality control (LQC) and higher quality control (HQC) level stored at $-22^{\circ}$ for $24 \mathrm{~h}$ and then thawed unassisted at room temperature. These freeze/ thaw cycle was repeated thrice. The short-term stability study was also determined at $-22^{\circ}$ for $12 \mathrm{~h}$. In addition, the long-term stability study for a period of $30 \mathrm{~d}$ was evaluated at both levels stored at $-22^{\circ}$. The results of stability study were compared against the freshly prepared QC samples ${ }^{[13]}$.

\section{Method applicability in pharmacokinetic study:}

The pharmacokinetic study was performed in accordance to the ethical guidelines of Committee for the Purpose of Control and Supervision of Experiment on Animals (CPCSEA) and the protocol was approved by the Institutional Animal Ethics Committee (IAEC) of Anand Pharmacy College, Anand, Gujarat, India (Protocol no. 1633). Rats were accommodated in plastic cages in a temperature controlled room $\left(20^{\circ} \pm 2^{\circ}\right)$ with a $12 \mathrm{~h}$ light/dark cycle. Female Wistar albino rats,

TABLE 1: FACTORS AND LEVELS FOR BBD

\begin{tabular}{lccc}
\hline \multirow{2}{*}{ Factors } & \multicolumn{3}{c}{ Levels } \\
\cline { 2 - 4 } & -1 & 0 & +1 \\
\hline A: Centrifugation speed $(\mathrm{rpm})$ & 6000 & 9000 & 12000 \\
B: Centrifugation time $(\mathrm{min})$ & 5 & 10 & 15 \\
$\mathrm{C}:$ Volume of plasma $(\mu \mathrm{l})$ & 100 & 200 & 300 \\
\hline
\end{tabular}


$250 \pm 10 \mathrm{~g}$, fasted overnight were used and had free access to water for at least $12 \mathrm{~h}$. Rats were divided into three groups. The first group as control group, second group received pure MET $(16.86 \mathrm{mg} / \mathrm{kg}$, orally (p.o.) and ALO (0.41 mg/kg, p.o.) and third group received prepared bilayer tablet formulation at same dose $\mathrm{e}^{[14,15]}$. After the administration, the blood samples $(\sim 500 \mu \mathrm{l})$ were collected from the retro orbital vein at $0,1,2$, 4, 6, 8, 10 and $12 \mathrm{~h}$ in sodium citrate tubes. Further, these blood samples were subjected to centrifugation at $4000 \mathrm{rpm}$ for $10 \mathrm{~min}$, followed by storage of the frozen plasma at $-20^{\circ}$ until analyzed. All the samples were further analyzed by determination of both the drugs within 6-7 $\mathrm{h}$ of blood collection by the method as described earlier. The pharmacokinetic parameters, area under the plasma concentration vs. time curve after oral administration (area under the curve, (AUC)), area under the first moment curve (AUMC) to the last measured plasma concentration, peak plasma concentration $\left(\mathrm{C}_{\max }\right)$, time to reach maximum plasma concentration $\left(\mathrm{t}_{\max }\right)$, elimination rate constant $\left(\mathrm{K}_{\mathrm{el}}\right)$, terminal elimination half-life $\left(\mathrm{t}_{1 / 2}\right)$, absorption rate constant $\left(\mathrm{K}_{\mathrm{ab}}\right)$ and absorption half-life $\left(\mathrm{t}_{1 / 2}\right)$ were determined for pure drugs and prepared bilayer formulation of MET and $\mathrm{ALO}^{[16-18]}$.

\section{RESULTS AND DISCUSSION}

Optimization of chromatographic conditions was carried out. Different mobile phases comprising varied ratio of water, methanol, acetonitrile with different buffers were tried but MET being highly polar was not retained on $\mathrm{C}_{18}$ column and so ion pairing reagent was used at different concentration to retain MET. Various ratio of 1-octane sulphonic acid $(10 \mathrm{mM})$, acetonitrile and phosphate buffer ( $\mathrm{pH} 4$ adjusted with orthophosphoric acid) resulted in acceptable peak shape for MET, ALO and TEN. This combination was further explored and the ratio was found suitable and the optimized gradient mobile phase, 1-octane sulphonic acid $(10 \mathrm{~mm})$, acetonitrile and phosphate buffer $\mathrm{pH} 4$ adjusted with orthophosphoric acid resulted in acceptable retention time of MET (6.11 $\mathrm{min})$, ALO (12.35 $\mathrm{min})$ and TEN (13.45 min), with theoretical plates (MET, 6473.56 $\pm 427.88 ;$ ALO, 52179.79 \pm 2501.94 ), tailing factor (MET, 1.225 $\pm 0.055 ; \quad$ ALO, $0.843 \pm 0.034$ ), appropriate resolution (MET and ALO 18.492 \pm 0.138 ; ALO and TEN, $4.679 \pm 0.048$ ) at $235 \mathrm{~nm}$ and flow rate of $1.0 \mathrm{ml} / \mathrm{min}^{[19,20]}$.

MET is a highly polar, basic compound with five nitrogen atoms in its structure. Hence, MET binds strongly leading to the poor recovery using cartridge and therefore it was not possible to extract it from biological fluids using an organic solvent or conventional SPE. Oasis ${ }^{\circledR}$ HLB cartridges are packed with a water wettable polymeric sorbent that allows greater flexibility in processing samples since it can dry out during the extraction procedure without diminishing its ability to retain analytes, thereby overcoming the drying out problem of the conventional silica based SPE cartridges ${ }^{[21]}$. Moreover, when MET was extracted using Oasis ${ }^{\circledR}$ HLB cartridge, it resulted in poor recovery of $5.0 \%$ of MET but recovery of ALO and TEN was more, 69.75 and $75.23 \%$ respectively.

For PP, percentage extraction recovery of MET $(91.42 \%)$ and ALO (80.90\%) from human plasma using methanol was higher as evident from results compared to acetonitrile and combined solvents ${ }^{[22]}$.

As per BBD design, total 17 experimental runs for optimization of PP extraction process were performed in a randomized fashion taking centrifugation speed, centrifugation time and volume of plasma as the CMPs and percentage extraction recovery of MET and ALO from the biological matrix as CAAs. Mathematical model selection on the basis of the data was done by fitting to the second-order quadratic model, with resulting model $\mathrm{p}$ value indicating significance of the model, $\mathrm{p}<0.05$ ( 0.0339 for MET and 0.0053 for $\mathrm{ALO})^{[23]}$. Adequate precision (7.31 for MET and 9.09 for ALO) and \% CV (9.54 for MET and 6.06 for ALO) were both in desirable limit. The threedimensional (3D) plots for percentage extraction recovery of MET and ALO shows that the influence of centrifugation speed and centrifugation time was found to be more on the percentage recovery of both the drugs (fig. 1A-fig. 1D). Moreover, percentage extraction recovery of both the drugs was inversely related to volume of plasma ${ }^{[24]}$. The polynomial equation revealing percent extraction recovery, R1 for MET was +70.669.2 A+8.32 B-9.53 C+8.93 AB-14.00 AC+0.75 BC-7.19 $\mathrm{A} 2-3.59 \mathrm{~B} 2-5.4 \mathrm{C} 2$ and for ALO, R2 was +74.40-6.95 $\mathrm{A}+8.09$ B-6.09 C+7.17 AB-12.20 AC+4.03 BC-10.51 $\mathrm{A} 2-3.60 \mathrm{~B} 2-5.18 \mathrm{C} 2$. The model was further validated by selecting the solutions suggested by design expert software version 7.0.0 and percent prediction error was calculated. Hence, the optimized condition for centrifugation speed, centrifugation time and volume of plasma considered as the CMPs for maximizing extraction recovery were $11800 \mathrm{rpm}, 15 \mathrm{~min}, 100 \mu \mathrm{l}$ (fig. 2). The CMPs optimized resulted in extraction recoveries of $91.24 \%$ of MET and $80.58 \%$ of ALO. 
www.ijpsonline.com

(A)

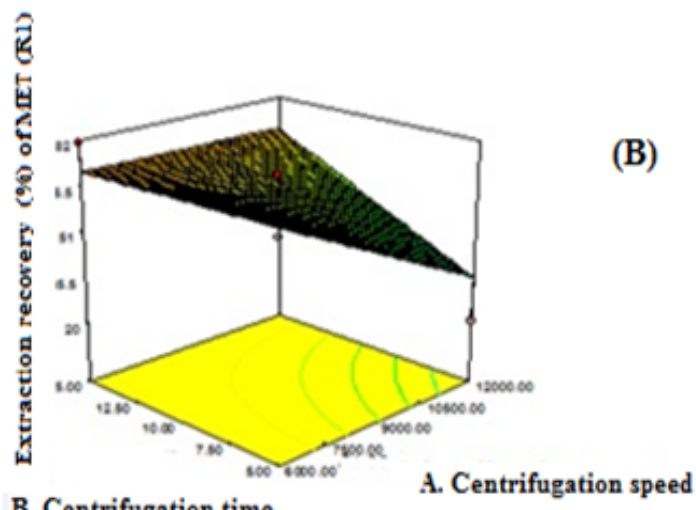

B. Centrifugation time

(C)

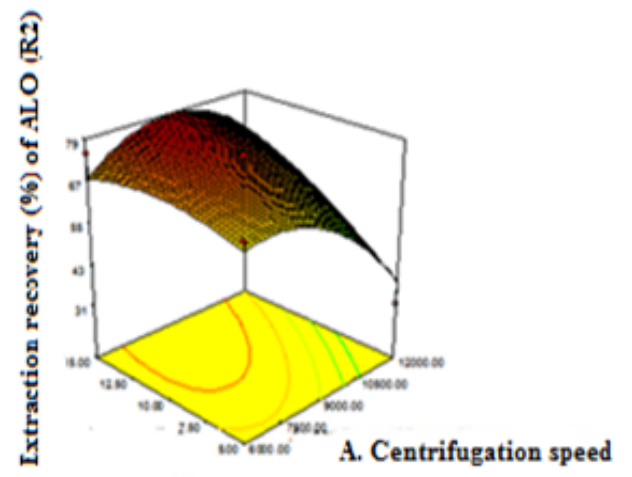

B. Centrifugation time

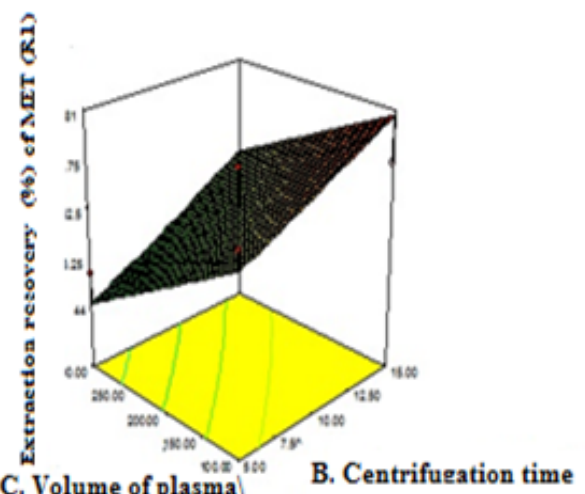

(D)

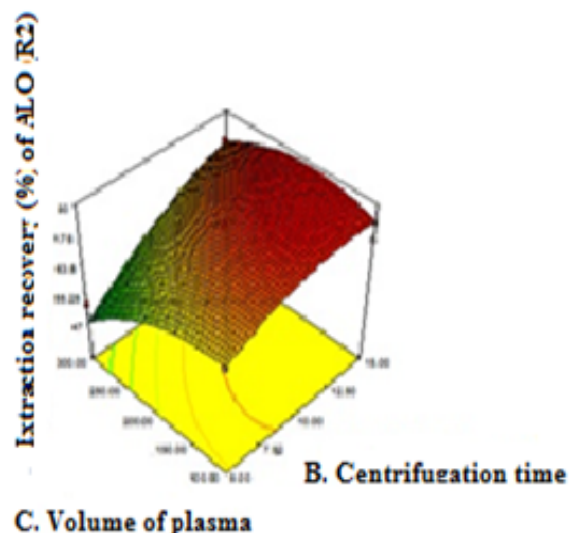

Fig. 1: 3D Response surface plot for (A) showing effect of centrifugation time and centrifugation speed on percent extraction recovery of MET; (B) showing effect of centrifugation time and volume of plasma on percent extraction recovery of MET; (C) showing effect of centrifugation time and centrifugation speed on percent extraction recovery of ALO; (D) showing effect of centrifugation time and volume of plasma on percent extraction recovery of ALO

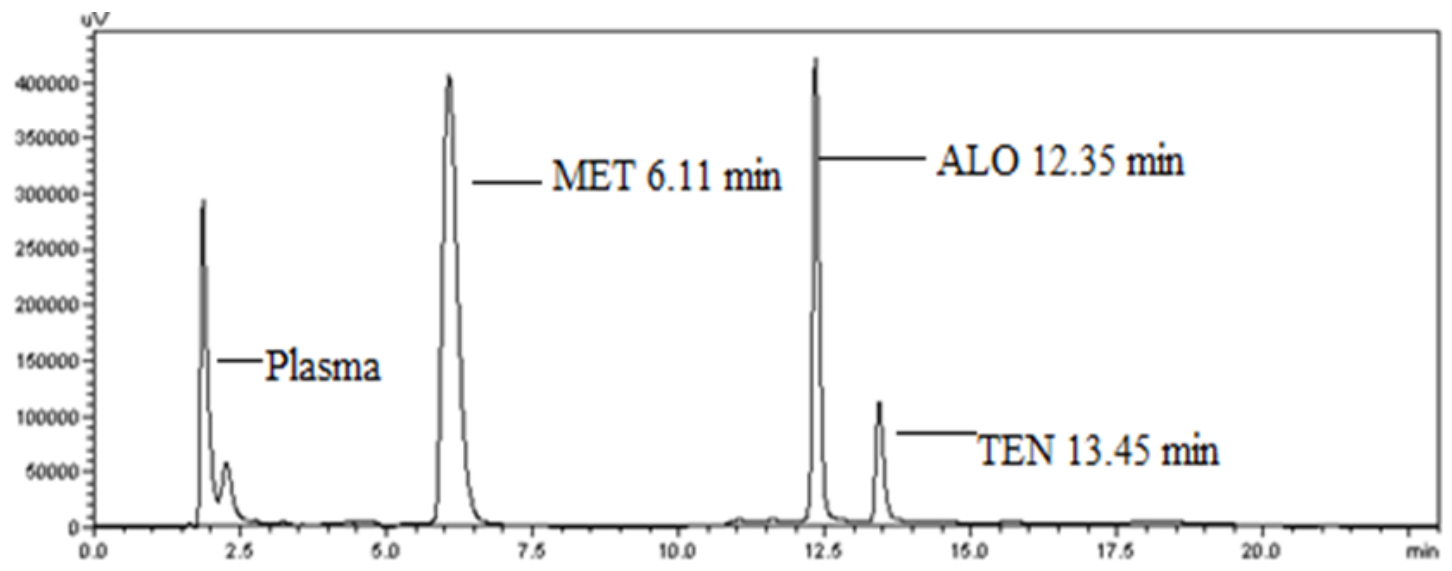

Fig. 2: Chromatogram showing optimized PP condition; centrifugation speed (11 $800 \mathrm{rpm})$, centrifugation time (15 min) and volume of plasma $(100 \mu \mathrm{l})$

Validation of bioanalytical method was carried out ${ }^{[25]}$. For both the drugs, linearity was obtained in the range of $0.022-2.2 \mu \mathrm{g} / \mathrm{ml}$ for MET and $0.0012-0.12 \mu \mathrm{g} / \mathrm{ml}$ for ALO with correlation coefficient of 0.9907 and 0.9918 respectively (Table 2). Furthermore, Bartlett's test revealed that the response of peak area for MET and ALO showed homogenous variance exemplified by the calculated $\chi^{2}$ value less than the tabulated value.
The sensitivity was measured in terms of LLOQ and mean percentage accuracy at LLOQ level was found to be $89.63 \pm 3.84 \%$ for MET $(0.022 \mu \mathrm{g} / \mathrm{ml})$ and $88.50 \pm 1.92 \%$ for ALO $(0.0012 \mu \mathrm{g} / \mathrm{ml})$. The selectivity was assured at LLOQ level where no other peak eluted at the retention times of MET (6.11 min), ALO (12.35 min) or TEN (13.45 min) in two different plasma lots (fig. 3). The accuracy determined at three QC levels 
TABLE 2: LINEAR REGRESSION PARAMETERS OF MET AND ALO

\begin{tabular}{|c|c|c|}
\hline Parameters & MET & ALO \\
\hline $\begin{array}{l}\text { Calibration range } \\
(\mu \mathrm{g} / \mathrm{ml})\end{array}$ & $0.022-2.2$ & $0.0012-0.12$ \\
\hline Regression equation $^{a}$ & $y=0.6749 x+0.3518$ & $=21.666 x+1.7315$ \\
\hline $\begin{array}{l}\text { Standard deviation } \\
\text { of slope }\end{array}$ & 0.015 & 0.688 \\
\hline $\begin{array}{l}\text { Confidence limit of } \\
\text { slope }^{c}\end{array}$ & $0.647-0.684$ & $19.87-21.48$ \\
\hline $\begin{array}{l}\text { Standard deviation } \\
\text { of intercept }\end{array}$ & 0.008 & 0.028 \\
\hline $\begin{array}{l}\text { Confidence limit of } \\
\text { intercept }^{c}\end{array}$ & $0.529-0.551$ & $2.35-2.42$ \\
\hline $\begin{array}{l}\text { Regression } \\
\text { coefficient }\left(R^{2}\right)\end{array}$ & 0.9907 & 0.9918 \\
\hline $\begin{array}{l}\text { Correlation } \\
\text { coefficient }(r)\end{array}$ & 0.9953 & 0.9958 \\
\hline LOD $(\mu \mathrm{g} / \mathrm{ml})$ & 0.040 & 0.004 \\
\hline LOQ ( $\mu \mathrm{g} / \mathrm{ml})$ & 0.123 & 0.013 \\
\hline Bartlett's test ${ }^{\mathrm{b}}\left(\mathrm{x}^{2}\right)$ & 0.0999 & 0.0423 \\
\hline
\end{tabular}

and \% CV was found to be less than 2.96 for MET and 2.67 for ALO confirming that the proposed method offers high accuracy. The precision measured in terms of \% CV was found to be less than 1.76 for MET and 3.30 for ALO at three QC levels resulting in high precision (Table 3 ). Moreover, mean percent extraction recovery for both the drugs was $90.83 \%-95.87 \%$ for MET and 94.03-96.73\% for ALO. The freeze/thaw stability, short-term and long-term stability studies carried out at two concentration (LQC, HQC) levels revealed \% CV less than 15 as per guidelines indicating stability of the both the drugs in plasma (Table 4).

The above validated bioanalytical method revealed the peaks of both drugs in chromatogram at same position without any interference in rat plasma. Pharmacokinetic profile showed higher $\mathrm{C}_{\max }(\mathrm{ng} / \mathrm{ml})$ for formulation (MET-3151.66 and ALO-698.2) compared to pure drugs (MET-2658.05 and ALO-688.2). For bilayer tablet formulation, AUC $(\mathrm{ng} \times \mathrm{h} / \mathrm{ml})$ for MET was 2235.59 compared to pure MET (1800.84). Similarly,

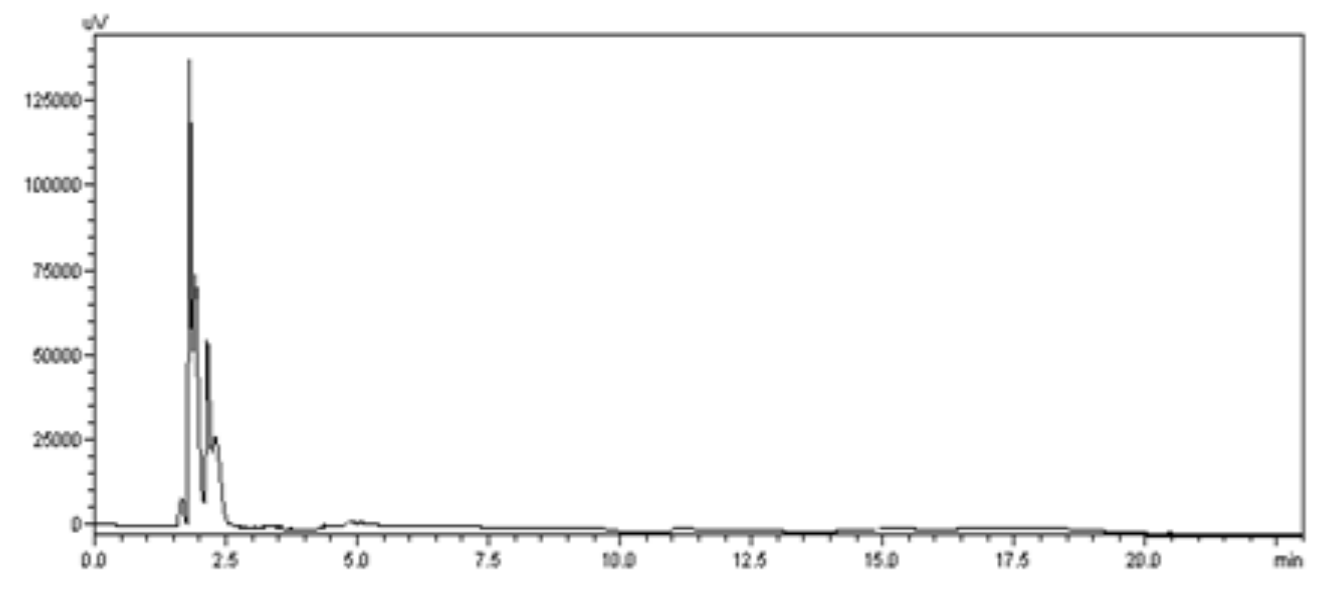

(A)

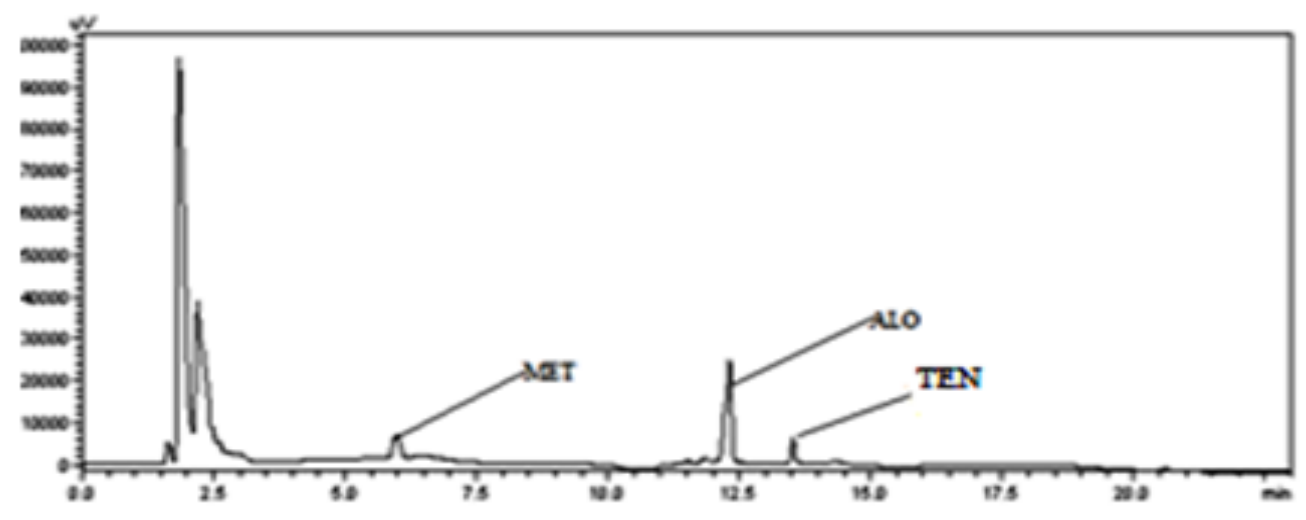

(B)

Fig. 3: Chromatograms representing method selectivity (A) blank plasma; (B) plasma spiked with MET, ALO and TEN 
for $\mathrm{ALO}, \mathrm{AUC}(\mathrm{ng} \times \mathrm{h} / \mathrm{ml})$ was 102 compared to pure drug (100.07). Additionally AUMC $(\mathrm{ng} \times \mathrm{h} / \mathrm{ml})$ for MET was 15352.08 compared to pure MET (11966.87). Similarly, for ALO, AUMC $(\mathrm{ng} \times \mathrm{h} / \mathrm{ml})$ was 477.05 compared to pure drug (442.66). This results reveals that the absorption of MET and ALO from formulation was higher as compared to pure MET and ALO (fig. 4). $\mathrm{T}_{\max }(3 \mathrm{~h})$ was similar for both pure drug and bilayer

TABLE 3: ACCURACY, PRECISION AND EXTRACTION RECOVERY OF MET AND ALO BY PROPOSED METHOD

\begin{tabular}{|c|c|c|c|c|c|c|c|c|}
\hline \multirow{2}{*}{ Accuracy } & & & \multicolumn{4}{|c|}{ Precision } & \multirow{2}{*}{\multicolumn{2}{|c|}{ Extraction recovery (\%) }} \\
\hline & & & \multicolumn{2}{|l|}{ Intraday } & \multicolumn{2}{|l|}{ Interday } & & \\
\hline $\begin{array}{l}\text { Concentration } \\
(\mu \mathrm{g} / \mathrm{ml})\end{array}$ & $\begin{array}{c}\text { Mean } \\
\text { concentration } \\
\text { found }^{\mathrm{a}}\end{array}$ & $\% \mathrm{CV}$ & $\begin{array}{c}\text { Mean } \\
\text { concentration } \\
\text { found }^{\mathrm{a}}\end{array}$ & $\% \mathrm{CV}$ & $\begin{array}{c}\text { Mean } \\
\text { concentration } \\
\text { found }^{\mathrm{a}}\end{array}$ & $\% \mathrm{CV}$ & $\begin{array}{c}\text { Mean } \\
\text { extraction } \\
\text { recovery }(\%)^{\mathrm{a}}\end{array}$ & $\% \mathrm{CV}$ \\
\hline \multicolumn{9}{|l|}{ MET } \\
\hline 0.045 & 0.0405 & 2.96 & 0.0409 & 1.76 & 0.0421 & 1.59 & 93.27 & 3.37 \\
\hline 0.45 & 0.4085 & 1.61 & 0.4077 & 1.66 & 0.4097 & 1.7 & 90.83 & 0.74 \\
\hline 1.5 & 1.398 & 0.8 & 1.3984 & 1.04 & 1.4009 & 1.05 & 95.87 & 0.95 \\
\hline \multicolumn{9}{|l|}{ ALO } \\
\hline 0.0024 & 0.0021 & 1.53 & 0.0021 & 2.09 & 0.0021 & 3.13 & 94.03 & 0.88 \\
\hline 0.024 & 0.022 & 1.28 & 0.0218 & 1.43 & 0.0219 & 3.14 & 94.67 & 1.32 \\
\hline 0.09 & 0.0829 & 2.67 & 0.082 & 3.3 & 0.081 & 0.49 & 96.73 & 1.25 \\
\hline
\end{tabular}

Note: amean of five replicates

TABLE 4: STABILITY STUDY BY PROPOSED BIOANALYTICAL METHOD

\begin{tabular}{|c|c|c|c|c|c|c|c|}
\hline & & $\begin{array}{c}\text { Nominal } \\
\text { concentration }(\mu \mathrm{g} / \mathrm{ml})\end{array}$ & $\begin{array}{c}\text { Mean extraction } \\
\text { recovery (\%) }\end{array}$ & $\% \mathrm{CV}$ & $\begin{array}{c}\text { Nominal } \\
\text { concentration }(\mu \mathrm{g} / \mathrm{ml})\end{array}$ & $\begin{array}{c}\text { Mean extraction } \\
\text { recovery (\%) }\end{array}$ & $\begin{array}{l}\% \\
\text { CV }\end{array}$ \\
\hline \multicolumn{4}{|c|}{ MET } & \multicolumn{4}{|c|}{ ALO } \\
\hline Freeze/thaw & LQC & 0.045 & 89.99 & 1.85 & 0.0024 & 87.47 & 0.65 \\
\hline stability & $\mathrm{HQC}$ & 1.5 & 93.24 & 0.85 & 0.09 & 93.29 & 3.18 \\
\hline Short-term & LQC & 0.045 & 91.89 & 1.51 & 0.0024 & 87.92 & 1.61 \\
\hline stability & $\mathrm{HQC}$ & 1.5 & 92.98 & 1.33 & 0.09 & 93.09 & 2.44 \\
\hline Long-term & LQC & 0.045 & 88.90 & 2.01 & 0.0024 & 88.22 & 1.69 \\
\hline stability & $\mathrm{HQC}$ & 1.5 & 93.04 & 1.31 & 0.09 & 93.12 & 2.87 \\
\hline
\end{tabular}

Note: average of three determinations

(A)

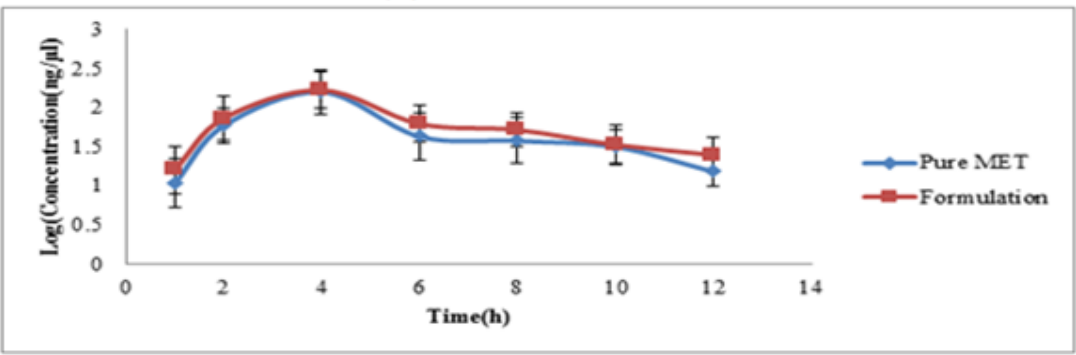

(B)

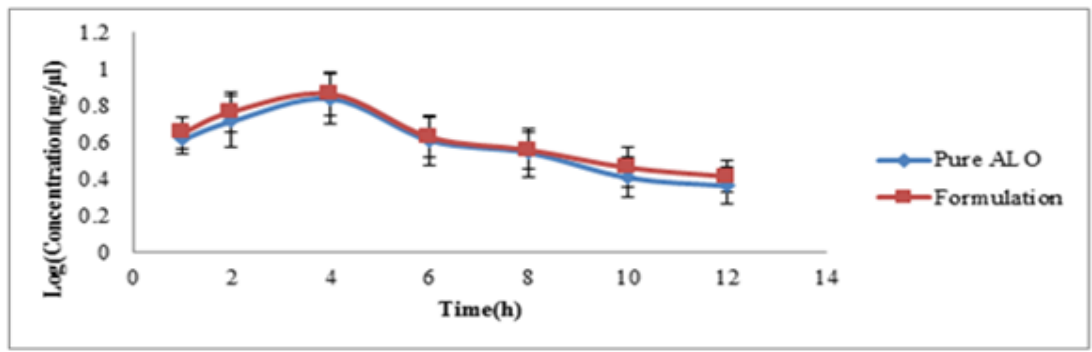

Fig. 4: Plasma concentration time profile for pure drug and bilayer tablet formulation (A) MET; (B) ALO 
tablet formulation. The above mentioned results reveal comparable pharmacokinetics and absorption profile with increase in AUC, AUMC for both the drugs with decrease in elimination ${ }^{[26]}$.

The proposed RP-HPLC method utilizes ion pairing reagent, 1-octane sulphonic acid for retaining MET on $\mathrm{C}_{18}$ column. The previous studies for simultanoeus estimation of MET and ALO in biological fluid, utilizes the sample preparation approaches like PP, LLE and SPE. While, the present research study proposed the development and application of a fast high throughput PP sample preparation method optimized by BBD for extraction of both the drugs from plasma with higher extraction recovery. Methanol was selected as the precipitating solvent owing to its polarity and gave high percent extraction recovery of both the drugs, $90.83 \%-95.87 \%$ for MET and $94.03-96.73 \%$ for ALO from plasma respectively ${ }^{[27,28]}$. The application of BBD hence assured the robust and reliable PP extraction technique and reveals higher extraction recovery, no requirement of specialized apparatus with faster analysis as well as low cost. Moreover, this optimized bioanalytical method also assures greater quantitation capability with good linearity. Additionally, the proposed validated HPLC bioanalytical method applied to pharmacokinetic study revealed higher plasma concentration of prepared bilayer tablet confirming greater absorption compared to pure drugs. Hence, a novel sensitive RP-HPLC bioanalytical method for the simultaneous estimation of MET and ALO in plasma was developed using ion pair reagent and validated revealing its capability for application in bioanalysis of MET and ALO in biological fluid sample.

\section{Conflict of interests:}

The authors declared no conflict of interest.

\section{REFERENCES}

1. Klip A, Leiter LA. Cellular mechanism of action of metformin. Diabetes care 1990;13(6):696-704.

2. Doupis J, Veves A. DPP4 inhibitors: a new approach in diabetes treatment. Adv Ther 2008;25(7):627-43.

3. Kumar AP, Aruna G, Rajasekar K, Reddy PJ. Analytical method development and validation of alogliptin and metformin hydrochloride tablet dosage form by RP-HPLC method. Int Bull Drug Res 2013;3(5):58-68.

4. Runja C, Ravikumar P, Avanapu SR. Stability indicating RP-HPLC method for simultaneous estimation of alogliptin benzoate and metformin hydrochloride in tablet dosage form. Int J Pharm Pharm Sci 2016;8:116-20.

5. Sri GS, Kumar SA, Saravanan J, Debnath M, Greeshma V, Krishna NS. A new stability indicating RP-HPLC method development for simultaneous estimation of metformin and alogliptin in bulk as well as in pharmaceutical formulation by using PDA detector. Indo Am J Pharm Res 2013;3:9222-41.

6. Kumar PK, Ahmed M, Shetty SA, Kuppast IJ, Siddalingaswamy MS, Ravi MC. RP-HPLC method development and validation for simultaneous estimation of alogliptin benzoate and metformin hydrochloride in combined tablet dosage form. World J Pharm Pharm Sci 2014;4:774-84.

7. Ashutosh KS, Manidipa D, Seshagiri R, Gowri SD. New validated stability indicating RP-HPLC method for simultaneous estimation of metformin and alogliptin in human plasma. J Chromatogr Sep Tech 2015;6(6):1-6.

8. Beg S, Chaudhary V, Sharma G, Garg B, Panda SS, Singh B. $\mathrm{QbD} \square$ oriented development and validation of a bioanalytical method for nevirapine with enhanced liquid-liquid extraction and chromatographic separation. Biomed Chromatogr 2016;30(6):818-28.

9. Tandel D, Shah P, Patel K, Thakkar V, Patel K, Gandhi T. Salting-out assisted liquid-liquid extraction for quantification of febuxostat in plasma using RP-HPLC and its pharmacokinetic application. J Chromatogr Sci 2016;54(10):1827-33.

10. FDA US. Guidance for industry: bioanalytical method validation. U.S. Department of Health and Human Services, Food and Drug Administration, Center for Drug Evaluation and Research (CDER), Center for Veterinary Medicine (CV); 2001.

11. Shah VP, Midha KM, Hill HM. Bioanalytical method validation-A revisit with a decade of progress. Pharm Res 2000;17:1551-7.

12. Sanford B. Pharmaceutical statistics. $2^{\text {nd }}$ ed. New York: Marcel Dekker Publication; 2004. p. 229-37.

13. Zar JH. Biostatistical analysis. $4^{\text {th }}$ ed. New Delhi: Pearson publishers; 2006. p. 202-4.

14. Porta V, Schramm SG, Kano EK, Koono EE, Armando YP, Fukuda $\mathrm{K}$, et al. HPLC-UV determination of metformin in human plasma for application in pharmacokinetics and bioequivalence studies. J Pharm Biomed Anal 2008;46(1) :143-7.

15. Chhetri HP, Thapa P, Van Schepdael A. Simple HPLCUV method for the quantification of metformin in human plasma with one step protein precipitation. Saudi Pharm J 2014;22(5):483-7.

16. Wanjari MM, There AW, Tajne MR, Chopde CT, Umathe SN. Rapid and simple RP-HPLC method for the estimation of metformin in rat plasma. Indian J Pharm Sci 2008;70(2):198202.

17. Polagani SR, Pilli NR, Gajula R, Gandu V. Simultaneous determination of atorvastatin, metformin and glimepiride in human plasma by LC-MS/MS and its application to a human pharmacokinetic study. J Pharm Anal 2013;3(1):9-19.

18. Pandya RH, Rathod R, Maheswari DG. Bioanalytical method development and validation for simultaneous determination of linagliptin and metformin drugs in human plasma by RPHPLC method. Pharmacophore 2014;5(2):202-18.

19. Bonde SL, Bhadane RP, Gaikwad AV, Katale DE, Gavali SU, Narendiran AS. A simple and sensitive method for determination of metformin and sitagliptin in human plasma using liquid chromatography and tandem mass spectrometry. Int J Pharm Pharm Sci 2013;5:463-70.

20. Chunduri RH, Dannana GS. Development and validation of LC-MS/MS method for simultaneous quantification of metformin and nateglinide in human plasma and its application to a pharmacokinetic study. World J Pharm Pharm Sci 2016;5:651-67. 
21. Ranetti MC, Ionescu M, Hinescu L, Ionica E, Anuta V, Ranetti $\mathrm{AE}$, et al. Validation of a HPLC method for the simultaneous analysis of metformin and gliclazide in human plasma. Farmacia 2009;57(6):728-35.

22. Deng J, Guo J, Dai R, Zhang G, Xie H. Determination of a novel dipeptidyl peptidase IV inhibitor in monkey plasma by HPLC-MS/MS and its application in a pharmacokinetics study. J Pharm Biomed Anal 2016;117:99-103.

23. Ranga S, Jaimini M, Sharma SK, Chauhan BS, Kumar A. A review on design of experiments (DOE). Int J Pharm Chem Sci 2014;3(1):216-4.

24. Bhatt DA, Rane SI. QbD approach to analytical RPHPLC method development and its validation. Int J Pharm Pharm Sci 2011;3(1):179-87.

25. Goday S, Shaik AR, Avula P. Development and validation of a LC-ESI-MS/MS based bioanalytical method for dapagliflozin and saxagliptin in human plasma. Indian J Pharm Educ Res 2018;52(4):S277-86.

26. Bayliss MA, Rigdova K, Kyriakides M, Grier S, Lovering AM, Williams $\mathrm{H}$, et al. Development, validation and application of a novel HPLC-MS/MS method for the measurement of minocycline in human plasma and urine. J Pharm Biomed Anal 2019;169:90-8.

27. Zuhri SH, Azad AK, Mia AR, Uddin AH, Nawi MS. Determination of cetirizine in human plasma and its validation of method using HPLC technique. J Drug Deliv Ther 2019;9(2):243-7.

28. Pinto MC, Berton DC, de Oliveira AC, Lazaro CM, Carandina SA. Method development and validation of ursodiol and its major metabolites in human plasma by HPLC-tandem mass spectrometry. Clin Pharmacol 2019;11:1-13. 